\title{
Aprendizagem tangencial no processo de ensino e aprendizagem de conceitos científicos: um estudo de caso
}

\author{
Bruno Silva Leite \\ Universidade Federal Rural de Pernambuco \\ leitebrunosilva@gmail.com
}

\begin{abstract}
Resumo: Com o objetivo de identificar filmes que podem ser utilizados no processo de ensino e aprendizagem de conteúdos científicos por meio da aprendizagem tangencial, este artigo relata os resultados de uma investigação realizada com oitenta e um (81) estudantes da licenciatura (química, física e biologia) e do mestrado em ensino de ciências de uma Universidade Federal. Para contemplar o objetivo central da pesquisa, uma abordagem qualitativa, consideramos o estudo de caso em cinco etapas. Os resultados se estruturam apresentando a análise das etapas da pesquisa, apontando uma postura favorável dos estudantes ao uso de filmes como estratégia para o ensino de conceitos científicos, por apresentarem características da aprendizagem tangencial.
\end{abstract}

Palavras-chave: Tecnologias no ensino, Ensino de Ciências, Aprendizagem Tangencial, Filmes.

\section{Tangential learning in the process of teaching and learning of scientific concepts: a case study}

Abstract: With the aim of identifying movies that can be used in the teaching and learning of scientific content through tangential learning, this article reports the results of research conducted with eighty-one students of degree (chemistry, physics and biology) and of the master in science education in a Federal University. In order to contemplate the central objective of the research, a qualitative approach, we consider the case study in five steps. The results are structured in the analysis of research steps, aiming for a favorable posture of the students to the use of films as a strategy for teaching scientific concepts, for presenting characteristics of tangential learning.

Keywords: Technology in education, Science Teaching, Tangential Learning, Movies.

\section{Introdução}

O crescente interesse na aplicação das Tecnologias Digitais da Informação e Comunicação (TDIC) em atividades relacionadas com o ensino e a aprendizagem nas instituições de ensino superior, tem levado a ruptura de métodos e metodologias tradicionais de ensino que por sua vez estão "cristalizados" com o tempo. Essas possibilidades quando incorporadas a prática pedagógica podem contribuir para a formação do cidadão consciente, autônomo, crítico e ativo na sociedade. As tecnologias criaram novos espaços de construção do conhecimento. Nesse sentido, os Recursos Didáticos Digitais (RDD) são meios e aparatos que podem ser utilizados pelo professor para auxiliar o ensino, e que utilizam diversas formas de expressão (texto, imagens, sons), para facilitar a construção do conhecimento dos estudantes.

A linguagem audiovisual predomina no mundo contemporâneo. Alguns trabalhos destacam o uso de filmes na educação (Worth, 1981; Machado, 2008; Coelho; Viana, 2011; Bastos et al., 2015). Sabendo-se da grande popularidade e impacto que os filmes têm, independente do seu gênero, por que não o utilizar em favor do aprendizado? Utilizar filmes na educação é considerada uma boa estratégia, quando planejada, facilitando aos professores discutirem com seus alunos os conteúdos disciplinares. E quando não há 
tempo para ver o filme durante a aula? Nessa pesquisa, apresentamos uma análise sobre a aprendizagem tangencial presente nos filmes e como a compreensão dos conceitos científicos envolvidos nestes, podem contribuir para o processo de ensino e aprendizagem. Ao mesmo tempo, esperamos suscitar alguma luz sobre os pressupostos que cercam essa temática de maneira a contribuir para futuras discussões.

\section{Aprendizagem Tangencial}

Jogos digitais e em especial os jogos populares podem ser usados para envolver os estudantes e estimular o interesse por temas específicos. Embora o conhecimento dos conteúdos não esteja explícito nos jogos, eles exigem a busca de informação por parte dos jogadores. Por exemplo, o jogo Age of Mythology apresenta um grande número de referências à mitologia antiga (Romana, Egípcia e Grega). Não é incomum que esse jogo faça que seus jogadores (curiosos sobre as referências e fontes descritas nele) passem a procurar e voluntariamente comecem a ler livros ou assistir a documentários sobre esses tópicos (Breuer; Bente, 2010). É nesse sentido que Portnow e Floyd (2008) propõem a ideia de aprendizagem tangencial, que considera que de alguma forma os jogos promovem o interesse na compreensão de certos conteúdos.

A aprendizagem tangencial ocorre quando "o aluno tem contato com o conhecimento sem perceber a intenção de ensiná-lo" (Leite, 2015, p. 135). Mesmo que a aprendizagem não ocorra dentro do jogo, criam-se cenários e desperta o interesse do estudante para a pesquisa sobre determinado assunto. Para que sejam levadas em conta estas oportunidades de aprendizagem tangenciais nos jogos, é recomendado que as referências dos jogos incluam links para recursos da web relevantes (Breuer; Bente, 2010).

Em alguns casos, os estudantes consideram que as aulas não são atraentes e por isso não se envolvem com elas e, consequentemente, não aprendem direito. Nesse sentido, a aprendizagem tangencial é importante para o processo de ensino e aprendizagem. $\mathrm{O}$ objeto de estudo não precisa ser necessariamente o tema principal do jogo digital. Para Breuer e Bente (2010) a estratégia do aprendizado tangencial também é um conceito promissor para promover mais aprendizado autodirigido e proativo. Consequentemente, os jogos digitais podem ser ferramentas importantes no processo de aprendizagem, motivadores e geradores de curiosidade.

\section{Materiais e métodos}

Para contemplar o objetivo central da pesquisa, que era identificar filmes que apresentam aprendizagem tangencial, lançou-se mão dos princípios da investigação qualitativa de cunho descritivo, do tipo levantamento (Gil, 2008; Lüdke; André, 2012). Nesse sentido, o trabalho foi desenvolvido como um estudo de caso, a fim de identificar filmes que podem ser utilizados no processo de ensino e aprendizagem, mas que não tem como foco de interesse a discussão dos conteúdos científicos.

A pesquisa foi dividida em cinco etapas: (1) Discussões sobre aprendizagem tangencial com os estudantes. Nesse momento, foram debatidos atributos da aprendizagem tangencial em sala de aula, contudo, direcionando-se a discussões sobre jogos que promovem essa aprendizagem; (2) Levantamento de filmes com potencial para uma aprendizagem tangencial. Nessa etapa, os estudantes realizaram um levantamento de filmes que envolvessem conteúdos científicos, mas que não apresentassem como tema principal a discussão conceitual desses conteúdos (por exemplo, filmes do tipo documentário); (3) Análise dos filmes selecionados pelo pesquisador. (4) Entrevista 
semiestruturada. Cada estudante assistiu três filmes e os relatos dessa experiência foram coletados por meio de um questionário com oito perguntas (tabela 1). (5) Realização de quatro debates sobre as percepções dos estudantes dos filmes, objetivando aos estudantes discutirem as potencialidades dos filmes escolhidos. Esse momento foi gravado em vídeo. Os vídeos apresentam em média cinquenta minutos de duração (cada) e os diálogos foram transcritos eliminando-se a possibilidade de identificação dos sujeitos. O debate ocorreu com a presença do pesquisador e se baseou na "escuta sensível" proposta por Barbier (2002). A escuta sensível "evoca a habilidade do observador em perceber e respeitar a fala do outro. Para ser sensível em escutar não deve compreender somente a audição, mas convocar os demais sentidos para perceber os gestos, os silêncios, as pausas, as emoções" (Stecanela, 2010, p. 146) dos participantes.

Tabela 1- Perguntas do questionário aplicado aos estudantes.

1. Quantos filmes você assiste por semana? a) pelo menos um; b) de um a três filmes; c) mais de quatro; d) pelo menos um por mês; e) não assisto.

2. Você já aprendeu algum conteúdo em um filme?

3. Você tinha certeza que aquele conteúdo estava correto? Explique.

4. Você acredita que um filme pode ser um recurso didático?

5. De acordo com sua resposta, explique por quê?

6. Como futuro professor, você indicaria algum filme para ajudar na compreensão de conteúdos de sala de aula? Justifique.

7. Quais conteúdos disciplinares você identificou nos filmes escolhidos?

8. Em sua opinião, que conceitos/conteúdos é possível aprender assistindo esses filmes?

Neste trabalho a unidade de análise da pesquisa é composta por oitenta e um (81) estudantes da Universidade Federal Rural de Pernambuco no semestre de 2016.1, dividido em quatro grupos, sendo sessenta e nove (69) de três cursos de licenciatura (vinte e três (23) de química, vinte e um (21) de física e vinte e cinco (25) de biologia) e doze (12) estudantes de mestrado em ensino de ciências.

\section{Resultados obtidos}

Na presente seção, apresentamos os resultados alcançados durante o processo de investigação da pesquisa. Primeiramente os resultados do levantamento filmográfico, destacando-se a análise dos filmes, em seguida a análise das respostas do questionário semiestruturado e ao final descrevemos algumas percepções dos estudantes obtidas durante os debates. As discussões relativas a Aprendizagem Tangencial (etapa 1) foram realizadas durante as aulas das disciplinas envolvidas, na forma de aula expositiva dialógica.

\subsection{Levantamento e análise dos Filmes}

Após as discussões da etapa 1 foi realizado o levantamento dos filmes pelos estudantes (etapa 2) e uma breve análise do pesquisador em relação aos filmes selecionados pelos estudantes (etapa 3). Ao todo foram indicados 44 filmes, entretanto, alguns filmes foram sugeridos por mais de um estudante. A classificação dos filmes selecionados para essa análise (Tabela 2), foram retiradas do Internet Movie Database (IMDb), um site que oferece uma base de dados online de informação sobre filmes, com cerca de 150 milhões de visitantes únicos mensais e mais de dois milhões de filmes (Boyle, 2014). 
Tabela 2 - Classificação dos filmes.

\begin{tabular}{|c|c|c|c|}
\hline Nome do filme & Ano & Gênero & IMDb* \\
\hline A culpa é das estrelas & 2014 & Drama / Romance & 7.8 \\
\hline A Guerra do Fogo & 1981 & Aventura / Drama & 7.4 \\
\hline À Procura da Felicidade & 2006 & Biografia / Drama & 8.0 \\
\hline A.I.: inteligência artificial & 2001 & Aventura / Drama / Ficção científica & 7.1 \\
\hline Alice no país das maravilhas & 2010 & Aventura / Fantasia & 6.5 \\
\hline Brilho eterno de uma mente sem lembranças & 2004 & Drama / Romance / Ficção científica & 8.3 \\
\hline Chernobyl - Sinta a Radiação & 2012 & Horror / Thriller / Ficção científica & 5.0 \\
\hline Clube da luta & 1999 & Drama & 8.8 \\
\hline Destruição Total: o fim do mundo & 2005 & Ação / Drama / Ficção Científica & 4.7 \\
\hline Era do Gelo 2 & 2006 & Animação / Comédia & 6.9 \\
\hline Exterminador do futuro: Genesis & 2015 & Ação / Aventura / Ficção Científica & 6.5 \\
\hline Homem aranha 2 & 2004 & Ação / Aventura & 7.3 \\
\hline Homem de Ferro & 2008 & Ação / Aventura / Ficção Científica & 7.9 \\
\hline Homem formiga & 2015 & Ação / Aventura / Ficção Científica & 7.4 \\
\hline Independence Day: o ressurgimento & 2016 & Ação / Aventura / Ficção Científica & 5.4 \\
\hline Interestelar & 2014 & Drama / Aventura / Ficção Científica & 8.6 \\
\hline Jogo da imitação & 2014 & Biografia / Drama / Thriller & 8.1 \\
\hline K-19 the widowmaker & 2002 & Drama / Thriller & 6.7 \\
\hline Lucy & 2014 & Ação / Thriller / Ficção Científica & 6.4 \\
\hline Mogli, o menino lobo & 2016 & Aventura / Drama & 7.6 \\
\hline No ar rarefeito, Morte no Everest & 1997 & Aventura / Biografia / Drama & 5.7 \\
\hline Náufrago & 2000 & Aventura / Drama / Romance & 7.7 \\
\hline O céu de outubro & 1999 & Biografia / Drama & 7.8 \\
\hline O dia depois de amanhã & 2004 & Ação / Aventura / Ficção Científica & 6.4 \\
\hline O dirigível Hindenburg & 1975 & Aventura / Drama & 6.2 \\
\hline O Menino do Pijama Listrado & 2008 & Drama & 7.8 \\
\hline O óleo de Lorenzo & 1992 & Drama & 7.2 \\
\hline O paciente Inglês & 1996 & Drama / Romance & 7.4 \\
\hline O vento será tua herança & 1999 & Drama & 7.4 \\
\hline Operação big hero & 2014 & Animação / Aventura / Ação & 7.9 \\
\hline Os Simpsons: o filme & 2007 & Animação / Aventura / Comédia & 7.4 \\
\hline Perdido em marte & 2015 & Aventura / Drama / Ficção Científica & 8.0 \\
\hline Perfume: A história de um assassino. & 2006 & Drama & 7.5 \\
\hline Planeta dos macacos: a origem & 2011 & Ação / Drama / Ficção Científica & 7.6 \\
\hline Primeiro da classe & 2008 & Drama & 8.2 \\
\hline Professor peso pesado & 2012 & Ação / Comédia & 6.5 \\
\hline Quarteto fantástico & 2005 & Ação / Aventura / Ficção Científica & 5.7 \\
\hline Resident Evil: O hóspede maldito & 2002 & Ação / Horror / Ficção Científica & 6.7 \\
\hline Sem limites & 2011 & Ficção Científica / Thriller & 7.4 \\
\hline Sociedade dos Poetas Mortos & 1989 & Comédia / Drama & 8.0 \\
\hline Uma mente brilhante & 2001 & Biografia / Drama & 8.2 \\
\hline Uma prova de amor & 2009 & Drama & 7.4 \\
\hline Viagem à lua de júpiter & 2013 & Ficção Científica / Thriller & 6.5 \\
\hline Viagem ao centro da terra: o filme & 2008 & Ação / Aventura & 5.8 \\
\hline
\end{tabular}

Os resultados obtidos da análise dos filmes escolhidos pelos estudantes (etapa 3) apresentam uma grande variedade de gêneros, contudo o gênero de Drama apresenta maior índice de escolha (Gráfico 1). 


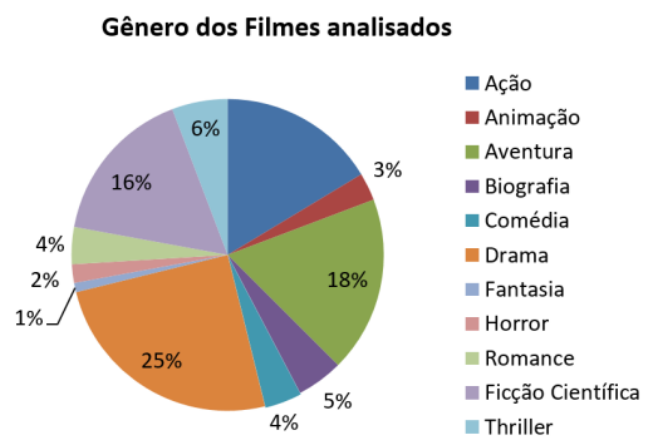

Gráfico 1 - Percentual de gêneros dos filmes sugeridos pelos estudantes.

Outro aspecto observado durante a análise dos filmes recomendados, além da diversidade de gêneros, é em relação ao ano de lançamento. Inicialmente, considerávamos que por tratar de estudantes com uma faixa etária entre 17 e 35 anos, os filmes indicados seriam do período de 2000-2016. Conforme observado, filmes de 1975 e 1981 foram sugeridos, ou seja, lançados em um período anterior ao nascimento de todos os envolvidos na pesquisa. É importante destacar essas escolhas, pois evidencia a atemporalidade dos filmes (Silva, 2011). Ademais, as notas atribuídas no IMDb são determinadas por equações e estatísticas, e nas sugestões observamos uma ampla disparidade nas notas pontuadas aos filmes (uns considerados bons e outros ruins pelo espectador).

\subsection{Análise das respostas da entrevista}

Apresentamos as respostas dos estudantes referentes a entrevista semiestruturada (etapa 4). Para manter a fidedignidade das respostas, as transcrições foram realizadas conforme escrito pelos estudantes, preservando-se erros de redação etc.

Quando questionados sobre o número de filmes que assistem (pergunta 1), 85,2\% dos estudantes responderam que assistem pelo menos um filme por semana, $11,1 \%$ até três por semana e 3,7\% assistem esporadicamente (pelo menos um filme por mês). Os filmes enriquecem as histórias apresentadas por meio do audiovisual, utilizando em alguns casos o conhecimento científico, retratando os momentos de forma mais realista, inspirando o público a compreender os fenômenos observados. Acreditamos que o ensino da Ciência em filmes, no contexto de um mundo fictício ou do mundo real, pode se tornar uma poderosa ferramenta pedagógica, já que as jovens e adultos (em sua maioria) têm em sua rotina assistir pelo menos um filme por semana.

Quando questionados se já aprenderam com algum filme (pergunta 2) apenas $35,8 \%$ dos estudantes afirmaram que sim. Esses dados corroboram com as ideias de Teruya e colaboradores (2013) que destacam possíveis dificuldades de aprendizado na visualização de algum conceito por parte dos estudantes. $\mathrm{O}$ entendimento de conceitos científicos, por exemplo na química, exige em alguns casos uma habilidade em compreender, relacionar e decodificar num nível de abstração complexo. Ainda nessa perspectiva, os estudantes que afirmaram aprender assistindo a filmes, foi questionado se eles tinham certeza de que o conteúdo estava correto (pergunta 3). Os resultados obtidos revelam que $31,1 \%$ disseram que sim e justificaram que "era um conceito que eu já tinha visto no ensino médio e me fez relembrar", "pela física dava para perceber que era coerente" e "a explicação fazia sentido". Já 68,9\% responderam não. Para ter certeza do que estava sendo discutido no filme era verdadeiro, eles "consultei no google", "eu tinha um livro de biologia que tinha o assunto, fui pesquisar nele" e "eu fiquei com tanta dúvida, que quando fui para a universidade perguntei ao professor de química se aquilo era verdade". Ambas as situações apresentadas evidenciam a presença de atributos da 
aprendizagem tangencial, que embora não seja objetivo do filme, motiva o interesse do estudante para a pesquisa sobre determinado assunto (Portnow; Floyd, 2008; Breuer; Bente, 2010). O fato do estudante buscar compreender os conceitos científicos no filme, revela que uma parte do que foi visualizado nele contribuiu para sua formação, ou seja, ocorre uma aprendizagem durante sua visualização.

Do questionamento se "Você acredita que um filme pode ser um recurso didático?" (pergunta 4), os resultados mostram que 91,4\% dos estudantes afirmam que o filme pode se configurar como um recurso didático. Quando solicitados para justificarem (pergunta 5), algumas respostas foram "ele pode ser utilizado de diferentes formas em sala de aula, então se posso usar em sala de aula, ele é um recurso", "o filme é um vídeo e o vídeo é um instrumento de ensino" e "o filme passa emoção, pode ser assistido em qualquer lugar, ele nos informa, nos diverte, nos ensina, e por isso ele pode ser um recurso para facilitar a aprendizagem". Os resultados apontam para as ideias de Leite (2015, p. 239) que considera o recurso didático digital como "um instrumento de trabalho na sala de aula que: informa, cria, induz à reflexão, desperta outros interesses, motiva, sintetiza conhecimentos e propicia vivências culturais". O filme se caracteriza como um RDD, pois tem como uma de suas características a portabilidade, ou seja, é possível ser utilizado em diferentes plataformas de trabalho. Ele não depende de outros para fazer sentido.

No sexto questionamento (Como futuro professor, você indicaria algum filme para ajudar na compreensão de conteúdos de sala de aula? Justifique), apenas dois alunos $(2,5 \%)$ responderam que "Não" e não justificaram suas respostas. Os demais responderam que "Sim". Algumas respostas são descritas: "[...] pode ajudar na compreensão de conteúdos difíceis por outra perspectiva", "Sim, acredito que vendo o filme é mais fácil aprender" e "É uma forma diferente de metodologia de ensino que rompe com o tradicionalismo do ensino em sala de aula e nos deixa curioso em pesquisar sobre". Os resultados consubstanciam com as ideias de Portnow e Floyd (2008) e Breuer e Bente (2010) sobre aprendizagem tangencial e com Souza et al. (2011) e Arroio e Giordan (2006) no que diz respeito ao efeito positivo dos vídeos em sala de aula. O filme tem seu potencial não necessariamente para educar, mas pode criar novas oportunidades para ensinar contribuindo para um melhor processo de ensino e aprendizagem.

Em relação aos conteúdos disciplinares identificados nos filmes (pergunta 7), observamos que em sua maioria eles estão presentes na disciplina de Química. O gráfico 2 descreve as áreas do conhecimento, classificadas pelo CNPq, dos conteúdos observados nos filmes por área de concentração.

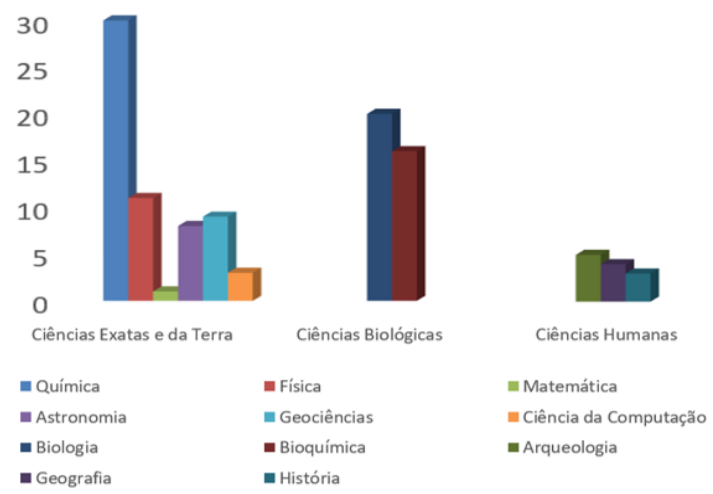

Gráfico 2 - Áreas do conhecimento presente nos filmes analisados.

Por fim a última questão "Em sua opinião, que conceitos/conteúdos é possível aprender assistindo esses filmes?", os estudantes foram concisos em suas respostas, algumas delas são reportadas a seguir: "Todos os conteúdos são possíveis", "[...] os 
conteúdos de química e física são mais fáceis, porém todos são possíveis, uns precisam de mais atenção, mas não são difíceis de aprender", "Basta ter atenção ao filme que dá pra aprender" e "Estamos aprendendo a todo momento, então acredito que ao assistir algum filme, eu já estou aprendendo". Esses estudantes afirmaram que o filme é uma ferramenta que pode ajudar no seu aprendizado, pois auxiliam não apenas nos conteúdos ligados à escola. Consideramos que as respostas dos estudantes pressupõem possibilidades da aprendizagem tangencial ser considerada como uma alternativa para 0 processo de ensino e aprendizagem de conceitos científicos.

\subsection{Percepções dos estudantes}

Após a realização das análises e respostas do questionário, os estudantes participaram de debates sobre os filmes vistos por eles (etapa 5). Ressaltamos alguns dos resultados que em nosso modo de ver, resultam ser mais interessantes para as discussões, considerando que destacar os 44 filmes não é necessário nesse momento.

Nesse sentido, destacamos alguns filmes e conteúdos debatidos pelos estudantes, contemplando os filmes que obtiveram mais de uma escolha por parte dos alunos, além dos filmes que apresentaram maiores discussões por turma. Durante as falas dos estudantes, os professores responsáveis pelas disciplinas (de cada turma) realizaram intervenções sobre as discussões levando em consideração os argumentos apresentados. Os alunos foram identificados por curso, para os da licenciatura: Q1, Q2... para os estudantes de Química; F1, F2... para os de Física; e B1, B2... para os de Biologia. Os estudantes do Mestrado foram identificados como M1 até M12.

Em todos os debates os professores iniciaram suas discussões a partir do filme "Independence Day: o ressurgimento", embora em cada grupo a sequência de filmes discutidos posteriormente tenham sido distintas, descrevemos os comentários e as conexões realizados pelos estudantes. A escolha para iniciar com este filme, justifica-se na perspectiva de analisarmos (a partir de um mesmo ponto de partida) as diferentes percepções e discussões que o diálogo no debate pode suscitar. Para o referido filme, o estudante Q11 afirma que "ele possibilita discussões na química e física como fissão e fusão nuclear, fusão a frio e campo magnético" e B2 apresenta uma outra perspectiva de aprendizagem tangencial no filme, pois para ele "Geografia e geologia estão presentes. $\mathrm{O}$ comportamento de um tornado e a compreensão do núcleo da Terra em relação aos seres vivos são observados no filme" e relaciona com o filme "O dia depois de amanhã", afirmando que o mesmo relata "conceitos de mudanças climáticas" (B2). Para esse mesmo filme o estudante Q22 atribui conceitos de química envolvidos, pois "[...] podese ver que a alta emissão de $\mathrm{CO}_{2}$ na atmosfera faz com que haja uma alteração climática no planeta, pois através de combustíveis fosseis há a liberação de $\mathrm{CO}_{2}$ que é uma reação de combustão". Para F7 o filme destaca também "conteúdos sobre aquecimento global e efeito estufa".

No debate dos filmes "Viagem à Lua de Júpiter", "Era do Gelo 2", "O fim do Mundo" e "Viagem ao centro da Terra: o filme" observamos, de forma geral, discussões sobre conteúdos científicos relacionados com Geologia, Geografia, Química e Biologia, em consonância com as considerações de Machado (2008). Através desses filmes podemos aprender, por exemplo, que o magnésio está presente em rochas e é inflamável; que a moscovita é um tipo de formação de rocha muito fina, de modo que a menor mudança de peso e pressão pode fazê-la quebrar; o xisto são vários tipos de rochas metamórficas facilmente identificáveis por serem fortemente laminadas; que o mineral feldspato é formado e encontrado geralmente em tubos vulcânicos; e que o interior da Terra vive em intensa atividade sísmica. 
No filme "O homem formiga" os estudantes Q1, Q9, Q14, Q16, Q19, Q22, Q23, F1, F13, F14, F20, M2, M7 e M9 destacam que o mesmo elucida de forma clara conceitos sobre o átomo, por exemplo, "O filme tem mecânica quântica, nanotecnologia e estrutura da matéria" afirma F13. Observamos que muitos filmes que tem cunho de aventura/ação com heróis fictícios retratam diversos conceitos da química, física e biologia, tais como: O homem de ferro, Quarteto fantástico, Homem aranha 2. O estudante Q18 destaca as discussões sobre Liga metálica presentes em dois filmes: "Operação Big Hero" e "O exterminador do futuro: genesis". Já sobre radiação F5 destaca os conteúdos abordados no filme "Quarteto Fantástico" e "Chernobyl: Sinta a Radiação".

O filme mais indicado pelos estudantes de físico foi "Interestelar". Para F18 “A relatividade de Einstein, com o conceito de espaço-tempo, comportamento temporal da gravidade são observados", F3 destaca "o funcionamento do Tomógrafo, uma tecnologia de ponta, desperta curiosidade" e F21 "[...] o buraco negro com suas teorias é uma boa".

Entre os estudantes de química, o filme mais citado foi "Perfume: a história de um assassino". O filme possibilita a percepção de alguns procedimentos químicos utilizados na produção de perfumes, bem como as técnicas envolvidas em tais procedimentos. Q1 destaca que "Aprendemos sobre os óleos essenciais e métodos de extração", já na perspectiva de Q6 "Ele (o filme) trata sobre funções oxigenadas e como a química está relacionada a fabricação dos perfumes" e "A análise química dos perfumes mostra que eles são uma complexa mistura de compostos orgânicos denominada fragrância" afirma Q21. Esse filme possibilita boas discussões sobre funções orgânicas, Marcelino Jr et al. (2004) retratam a interferência positiva de um vídeo utilizando "perfumes e essências" como tema motivador, realizando uma intervenção didática, abrangendo atividades audiovisuais, leitura e escrita de textos. O segundo filme mais escolhido foi "O óleo de Lorenzo", embora seja baseado em fatos reais, possibilita a compreensão dos processos bioquímicos e síntese orgânica a partir da mistura de substâncias. Segundo Q16 "a combinação de gorduras extraídas de itens de cozinha comuns como óleo de oliva virgem e óleo de colza, permitiram a criação do óleo de Lorenzo. Eu pesquisei e vi que a química explica isso por meio dos conteúdos de misturas, soluções, reações químicas e orgânicas". Esse relato nos conduz a conjecturar sobre as contribuições dos filmes numa perspectiva de aprendizagem tangencial (Breuer; Bente, 2010; Leite, 2015).

Para os estudantes de Biologia "Perdido em Marte" foi o filme mais indicado. Eles destacam os pressupostos do clima de Marte, reproduzindo tempestades violentas e as temperaturas extremamente baixas em comparação às da Terra. Para B6 é interessante quando o filme mostra suposições da "geologia do planeta, mostrando o aspecto da superfície, cor do solo, erosão, cadeias de montanhas, aspecto das partículas de sedimentos e da atmosfera, pois nos faz pensar a respeito". No tocante a decomposição catalítica, os estudantes consideram "um aprendizado interessante, pois nos mostra como tentar sobreviver em ambientes diferentes da Terra" (B8) e "um módulo de sobrevivência em ambientes inóspitos". A comunicação através de uma tabela de hexadecimais é também pontuada pelos estudantes. B14 relata: "eu pesquisei sobre as reações químicas e leis da termodinâmica, e vi que elas nos ajudam a compreender os processos químicos e biológicos que foram usados na sobrevivência", atributos da aprendizagem tangencial.

Para os estudantes de mestrado, embora sejam do ensino de ciências, não observamos filmes que tenham sido sugeridos por mais de uma vez. Cabe ressaltar que, os filmes Interestelar, Viagem à lua de júpiter e Perdido em Marte abordam conceitos da astronomia, química, física, engenharia aeroespacial, astrobiologia e astrodinâmica, de maneira quase interativa e simplificada a ponto de ser compreendidos pelos espectadores mesmo que não possuam afinidade prévia sobre os temas nos quais as obras se sustentam, permitindo a compreensão e assimilação de, pelo menos, algum conhecimento. 
Conforme descrito por Coelho e Viana (2011, p. 92) "o uso de filmes em sala de aula pode tornar as aulas dinâmicas e o cotidiano escolar passa a ser menos cansativo para professores e alunos". Compreender que o filme não precisa ser rigorosamente coerente e que não necessita expressar a realidade científica, mas que pode ser um ótimo recurso é um dos pressupostos fundamentais ao professor no uso desse RDD. Não é imprescindível querer explorar o filme em sua totalidade, no intuito de explica-lo integralmente. Porém, contemplar as contradições do filme e suas "distorções" em relação a realidade, pode configurar uma boa estratégia didática que possibilita o aprofundamento do conteúdo e a reflexão sobre o tema. A realização de mais atividades diferenciadas pode contribuir para o engajamento dos estudantes, além de proporcionar resultados positivos quanto ao processo de aprendizagem do aluno. A mudança de algumas práticas pode ser um caminho para que o professor obtenha êxito no processo de ensino e aprendizagem.

Por fim, cabe ressaltar que utilizar cenas de filmes como pressuposto para iniciar discussões em sala de aula, pode ser um recurso didático favorável no processo de ensino e aprendizagem. Para um dos alunos "ver os filmes foi uma experiência muito boa" (M6) e que "agora vou assistir os filmes com outra percepção" (Q7), evidenciando o potencial do uso dos filmes como ferramenta de aprendizagem (Leite, 2015). Ademais, discutir o quanto os filmes podem contribuir em relação ao conhecimento científico na formação do cidadão e o quanto o conhecimento adquirido na escola pode contribuir para seu dia a dia, pode ser de extrema importância. $\mathrm{O}$ fato dos estudantes conseguirem discernir do que é verdadeiro e o que é fictício nos filmes, favorece a formação de um cidadão crítico, autônomo, participativo e transformador.

\section{Considerações finais}

Este estudo procurou identificar possíveis relações de filmes com atributos da aprendizagem tangencial. Os filmes são recursos disponíveis ao professor, por meio deles podemos aproximar nossos alunos, explorando diversas possibilidades. A familiaridade dos estudantes com os filmes em seu contexto social, pode ser um aliado no processo de aprendizagem do mesmo. Um aspecto positivo é que existem filmes tratando praticamente de tudo, o papel do professor, nesse sentido, seria o de selecionar os mais adequados.

A análise dos filmes e as percepções dos estudantes mostraram, por um lado, que embora não seja sua intenção, os filmes apresentam contributos na aprendizagem do espectador e, por outro, são suscetíveis a aprendizagem tangencial. Conforme descrito por Leite (2015, p. 313), o uso de vídeos (filmes) "traz a possibilidade de utilizar não somente palavras, mas também imagens, muitas vezes bem mais atrativas e persuasivas do que a fala do(a) professor(a), podendo trazer um impacto muito maior do que o de um livro ou de uma aula expositiva". Nesse contexto, acreditamos que os filmes podem contribuir na construção do conhecimento, não sendo necessariamente seu foco principal, mas que "lançam" as dúvidas, geram os questionamentos se de fato o que é abordado é ficção ou trata-se de um conceito "real", promovendo a busca dos alunos em descobrirem os eventos visualizados. O problema não é mais a informação, mas o modo de se construir o aprendizado.

Os filmes podem ser utilizados em diferentes níveis de ensino, dependendo da intenção e propósito do professor. Eles podem permitir uma compreensão e identificação dos conteúdos que serão abordados ou dos conteúdos vivenciados em sala de aula. É perceptível que o uso dos filmes no processo de ensino e aprendizagem podem contribuir para esse processo, mesmo que não seja o objetivo do mesmo (configurando uma aprendizagem tangencial). Ademais, acreditamos que nesse processo, o professor pode 
promover estratégias que conduzam uma aprendizagem significativa, tangencial e mais aberta, por meio do uso dos diversos recursos didáticos digitais.

Por fim, cabe ressaltar que o uso de filmes de maneira constante em sala de aula, não é o indicado. A ideia é que o uso do filme, como de qualquer TDIC, ocorra por meio de estratégias, se adequando as necessidades e capacidade real de cada situação, possibilitando a transformação da prática pedagógica, visando a construção do conhecimento mais flexível e dinâmico dos envolvidos.

\section{Referências bibliográficas}

ARROIO, A.; GIORDAN, M. O vídeo educativo: aspectos da organização do ensino. Química Nova na Escola, v. 24, n.1, p. 8-11, 2006.

BARBIER, R. Escuta sensível na formação de profissionais de saúde. Conferência na Escola Superior de Ciências da Saúde. Brasília, 2002. Disponível em: <http://www.barbier-rd.nom.fr/ESCUTASENSIVEL.PDF>. Acesso: 20 set. 2016.

BASTOS, W. G.; REZENDE FILHO, L. A. C.; PASTOR JUNIOR, A. A. Produção de vídeo educativo por licenciandos: um estudo sobre recepção fílmica e modos de leitura. Revista Ensaio, v. 17, n. 1, p. 39-58, 2015.

BOYLE, K. Gender, comedy and reviewing culture on the Internet Movie Database. Participations: Journal of audience \& Reception Studies, v.11, n.1, p. 31-42, 2014.

BREUER, J. S.; BENTE, G. Why so serious? On the Relation of Serious Games and Learning. Journal for Computer Game Culture, v. 4, n. 1, p. 7-24, 2010.

COELHO, R. M. F.; VIANA, M. G. V. A utilização de filmes em sala de aula: um breve estudo no instituto de ciências Exatas e biológicas da UFOP. Revista da Educação Matemática da UFOP, v. 1, p. 89-97, 2011.

GIL, A. C. Métodos e técnicas de pesquisa social. $6^{\text {a }}$ ed. São Paulo: Atlas, 2008.

LEITE, B. S. Tecnologias no ensino de química: teoria de prática na formação docente. Curitiba: Appris, 2015.

LÜDKE, M.; ANDRÉ, M. E. D. A. Pesquisa em educação: abordagens qualitativas. São Paulo: E.P.U., 2012.

MACHADO, C. A. Filmes de ficção científica como mediadores de conceitos relativos ao meio ambiente. Ciência \& educação, v. 14, n. 2, p. 283-294, 2008.

MARCELINO-JR., C. A. C.; BARBOSA, R. M. N.; CAMPOS, A. F.; LEÃO, M. B. C.; CUNHA, H. S.; PAVÃO, A. C. Perfumes e essências: a utilização de um vídeo na abordagem das funções orgânicas. Química Nova na Escola, v. 19, n.1, p. 15-18, 2004. PORTNOW, J.; FLOYD, D. Tangential learning concept for learning contentes. In videogames. E-innova, Madrid, n. 5, 2008.

SILVA, G. B. Aprendendo Cinema: Um Arquivo do Cinema Técnico. Joinville: Clube de Autores Publicações, 2011.

SOUZA, C. L.; FRANCISCO JUNIOR, W. E.; MARTINES, E. A. L. M. Vídeos educativos para o ensino de química: alguns apontamentos sobre o telecurso 2000. In: VIII Encontro Nacional de Pesquisa, Campinas (SP), p. 1-12, 2011.

STECANELA, N. Jovens e Cotidiano: trânsitos pelas culturas juvenis e pela escola da vida. Caxias do Sul: Educs, 2010.

TERUYA, L. C.; MARSON, G. A.; FERREIRA, C. R.; ARROIO, A. Visualização no ensino de química: apontamentos para a pesquisa e desenvolvimento de recursos educacionais. Química nova, v. 36, n. 4, p. 561-569, 2013.

WORTH, S. The Uses of Film in Education and Communication. In: Larry Gross (Ed.). Studying Visual Communication. Philadelphia: University of Pennsylvania Press, p. 108-133, 1981. 